age 16 were more likely to be described as clumsy. Delays in learning to stand, walk or speak are linearly related to later risk of schizophrenia (Isohanni et al, 2001) as also was delay in potty-training, a finding that corresponds to an increased incidence of failures of continence observed in the NCDS cohort.

Each of these findings suggests some commonality between features of pervasive developmental disorders (including Asperger syndrome) and those that precede schizophrenia, notwithstanding obvious differences in methods of data collection. There remains the question of time course to which Asperger drew attention-the features of Asperger syndrome are present early, whereas those of schizophrenia show an element of progression. This difference is exemplified by a progressive decrease in language scores preceding the onset of schizophrenia (Fuller et al, 2002).

The key question is why does this constellation of features come together? One finding from the NCDS sample points to the neurological substrate. At age 7, children who, in adulthood, develop schizophrenia were more likely to be rated as ambidextrous for handwriting by their mothers and were less lateralised on a square ticking task at age 11 . There is evidence that lateralisation is a major determinant of the acquisition of words as well as of other aspects of cognitive ability (Crow $e t$ al, 1998). We propose that development of hemispheric dominance for the components of language is relevant to the similarities of the conditions described by the term Asperger syndrome and those that precede the onset of schizophrenic psychoses, as well as to differences in their time course. Thus, language - the core characteristic of the species - with its context in social interaction and its matrix in the lateralisation to the two hemispheres, is the function that varies between individuals and accounts for the similarities between the early developmental anomalies that were identified by Asperger and those that can now be seen as precursors to psychotic illness.

American Psychiatric Association (1980) Diagnostic and Statistical Manual of Mental Disorders (3rd edn) (DSM-III).Washington, DC: APA.

- (1994) Diagnostic and Statistical Manual of Mental Disorders (4th edn) (DSM-IV). Washington, DC: APA.

Asperger, H. (1944) Die 'Autistischen Psychopathen' im Kindesalter (translated as 'Autistic psychopathy' in childhood). Archiv für Psychiatrie und Nervenkrankheiten, II7, 76-136. In U. Frith (ed.) (1991) Autism and Asperger Syndrome. Cambridge: Cambridge University Press.
Crow, T. J., Crow, L. R., Done, D. J., et al (1998) Relative hand skill predicts academic ability: global deficits at the point of hemispheric indecision. Neuropsychologia, 36, 1275-1282.

Done, D. J., Crow, T. J., Johnstone, E. C., et al (1994) Childhood antecedents of schizophrenia and affective illness: social adjustment at ages 7 and II. BMJ, 309, 699-703

Ehlers, S. \& Gillberg, C. (1993) The epidemiology of Asperger syndrome: a total population study. Journal of Child Psychology and Psychiatry, 34, 1327-1350.

Fuller, R., Nopoulos, P., O’Leary, D., et al (2002) Longitudinal assessment of premorbid cognitive functioning in patients with schizophrenia through examination of standardized scholastic test performance. American Journal of Psychiatry, 159, II83-1189.

Isohanni, M., Jones, P. B., Moilanen, K., et al (200I) Early developmental milestones in adult schizophrenia and other psychoses. A 31-year follow-up of the Northern Finland 1966 cohort. Schizophrenia Research, 52, $1-19$.

Tantam, D. (1988) Lifelong eccentricity and social isolation I. Psychiatric, social, and forensic aspects. British Journal of Psychiatry, 153, 777-791.

World Health Organization (1992) The ICD-I0 Classification of Mental and Behavioural Disorders. Geneva: WHO

S. J. Leask University Department of Psychiatry, Duncan Macmillan House, Porchester Road, Nottingham NG3 6AA, UK

D. J. Done Psychology Division, University of Hertfordshire, UK

T. J. Crow POWIC, University Department of Psychiatry, University of Oxford, UK

\section{Genetics of early-onset depression}

We were very interested to read the recent, thought-provoking editorial by Andrews et al (2002) on the prevention of depression in young people. However, we are concerned that they have understated the important role of genetics in early-onset depression. Contrary to their assertion that the children of parents with depression are likely to be at heightened risk for psychological rather than genetic reasons, available evidence suggests that childhood-onset depression represents a strongly genetic subtype of affective disorder (Neuman et al, 1997; Sullivan et al, 2000). Up to $50 \%$ of prepubertal children with depression eventually develop bipolar disorder (Geller et al, 2001) and recurrent, early-onset depression (defined as two or more episodes before age 25 ) is recognised as a malignant form of affective disorder characterised by high genetic loading, frequent recurrence and poor long-term outcome (Zubenko et al, 2001). Furthermore, one recent study suggests that the inheritance of depression in these families is compatible with a single major locus (Maher et al, 2002).
Preliminary findings from our own study of early-onset depression in a university population support the view that early age at onset defines a subgroup at very high genetic risk. Using the Family Interview for Genetics Studies (FIGS; National Institute of Mental Health, 1999), $76 \%$ of the subjects seen so far (36 out of 47 ) report at least one first-degree relative with affective disorder, with $87 \%$ ( 41 out of 47 ) reporting either a first- or second-degree relative affected. The mean age at onset in this group is 15.6 years $($ s.d. $=2.6$ ).

Population-based interventions are unlikely to reduce the prevalence of depression in young people as long as we have an incomplete understanding of how genetic and non-genetic risk factors interact to bring about the depressive phenotype. Interventions such as the cognitive therapy programme described by Clarke and colleagues (Clarke et al, 2001) might be costeffective strategies if they can be targeted to high-risk groups. Unfortunately, we are not yet in a position to reliably identify those individuals at high risk.

Andrews, G., Szabo, M. \& Burns, J. (2002) Preventing major depression in young people. British Journal of Psychiatry, 18I, 460-462.

Clarke, G. N., Hornbrook, M., Lynch, F., et al (200I) A randomised trial of group cognitive intervention for preventing depression in adolescent offspring of depressed parents. Archives of General Psychiatry, 58, II27-II34.

Geller, B., Zimmerman, B., Williams, M., et al (200I) Bipolar disorder at prospective follow-up of adults who had prepubertal major depressive disorder. American journal of Psychiatry, 158, 125-127.

Maher, B., Marazita, M. L., Zubenko,W. N., et al (2002) Genetic segregation analysis of recurrent, earlyonset depression: evidence for single major locus transmission. American Journal of Medical Genetics, II4 214-22I.

National Institute of Mental Health (1999) FIGS face sheet. http: //zork. wustl.edu/nimh/figs/FIGS.pdf

Neuman, R. J., Geller, B., Rice, J. P., et al (1997) Increased prevalence and earlier onset of mood disorders among relatives of prepubertal versus adult probands. Journal of the American Academy of Child and Adolescent Psychiatry, 36, 466-473.

Sullivan, P., Neale, M. C. \& Kendler, K. S. (2000) Genetic epidemiology of major depression: review and meta-analysis. American Journal of Psychiatry, 157, 1552-1562.

Zubenko, G., Zubenko, W. N., Spiker, D. G., et al (200I) Malignancy of recurrent, early-onset depression: a family study. American Journal of Medical Genetics, 105 690-699.

D. Smith, W. Muir, D. Blackwood Department of Psychiatry, School of Molecular and Clinical Medicine, The University of Edinburgh, Kennedy Tower, Royal Edinburgh Hospital, Morningside Park, Edinburgh EHIO 5HF, UK 